MATEC Web of Conferences 45, 04009 (2016)

DOI: $10.1051 /$ matecconf/20164504009

(C) Owned by the authors, published by EDP Sciences, 2016

\title{
Procedure for the automatic mesh generation of innovative gear teeth
}

\author{
Andrea Chiaramonte Radicella ${ }^{1}$, Giulio Di Francesco ${ }^{2}$, Vincenzo La Battaglia ${ }^{2}$, Stefano Marini ${ }^{2}$ \\ ${ }^{1}$ Toyota Motor Europe, Avenue Du Bourget 60, 1140 Ville de Bruxelles, Belgium \\ ${ }^{2}$ Università degli Studi Roma Tre - Dipartimento di Ingegneria, Via della Vasca Navale 79, 00146 Roma, Italy
}

\begin{abstract}
After having described gear wheels with teeth having the two sides constituted by different involutes and their importance in engineering applications, we stress the need for an efficient procedure for the automatic mesh generation of innovative gear teeth. First, we describe the procedure for the subdivision of the tooth profile in the various possible cases, then we show the method for creating the subdivision mesh, defined by two series of curves called meridians and parallels. Finally, we describe how the above procedure for automatic mesh generation is able to solve specific cases that may arise when dealing with teeth having the two sides constituted by different involutes.
\end{abstract}

\section{Introduction}

In recent years the studies and applications of gear wheels with teeth having the two sides constituted by different involutes are increasing [1-5].

These innovative wheels (different pressure angles for the two sides of the tooth: $\alpha_{01}$ and $\alpha_{02}$ ) have some considerable advantages [6]; the tooth is more robust: with other factors being equal, they can transmit a higher torque; on equal torque to be transmitted, their overall size is reduced.

Their applications are manifold, particularly in transmissions in which there is only one direction of rotation: speed gear box in automotive transmissions, gear pumps, etc.

By way of example, the following figures 1 and 2 show the traditional profile with $\alpha_{01}=\alpha_{02}=20^{\circ}$ compared with the profiles of innovative teeth characterized by $\alpha_{01}$ and $\alpha_{02}$ equal to, respectively: $20^{\circ}-14^{\circ}, 20^{\circ}-16^{\circ}$, $20^{\circ}-24^{\circ}, 20^{\circ}-26^{\circ}$.

As you can see, the geometrical difference varies as the angles $\alpha_{01}$ and $\alpha_{02}$ of the two sides of the tooth, the left side and the right side, vary.

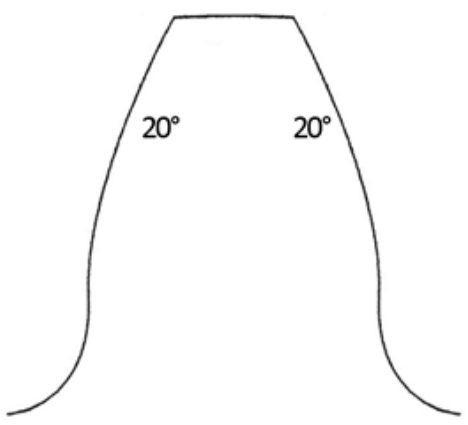

Figure 1. Traditional profile with $\alpha_{01}=\alpha_{02}=20^{\circ}$
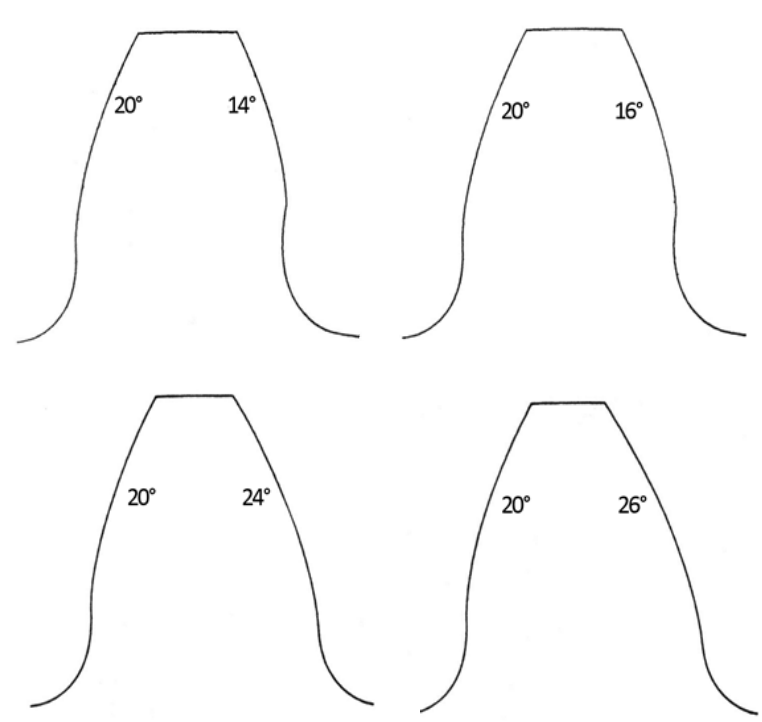

Figure 2. innovative teeth profile with $\alpha_{01}=20^{\circ}$ and different value of $\alpha_{02}$

The variation in the second pressure angle, permits to vary the robustness of the tooth and hence to increase transmission performance [7] [8]. However, the quantification of this increase in performance cannot be estimated other than through a prior FEM analysis of the tooth. This analysis is in any case limited by the absence of an automatic and efficient mesh generator for the tooth structure [9-13].

The meshing system that we intend to propose is based on the subdivision of the tooth through a network of "meridians" and "parallels": the "meridians" are roughly composed of circular arcs, the "parallels", on the other hand, are curves with a trend similar to that of the tooth profile. 


\section{Subdivision of the tooth profile}

The first step in the meshing of the tooth consists in the subdivision of its profile.

The tooth profile presents itself as the succession of various curves with a variable radius of curvature. The subdivision of this profile must follow said variability increasing the number of elements in the areas with a smaller radius of curvature so as to thin it out as the same radius of curvature increases (see figure 3 ).

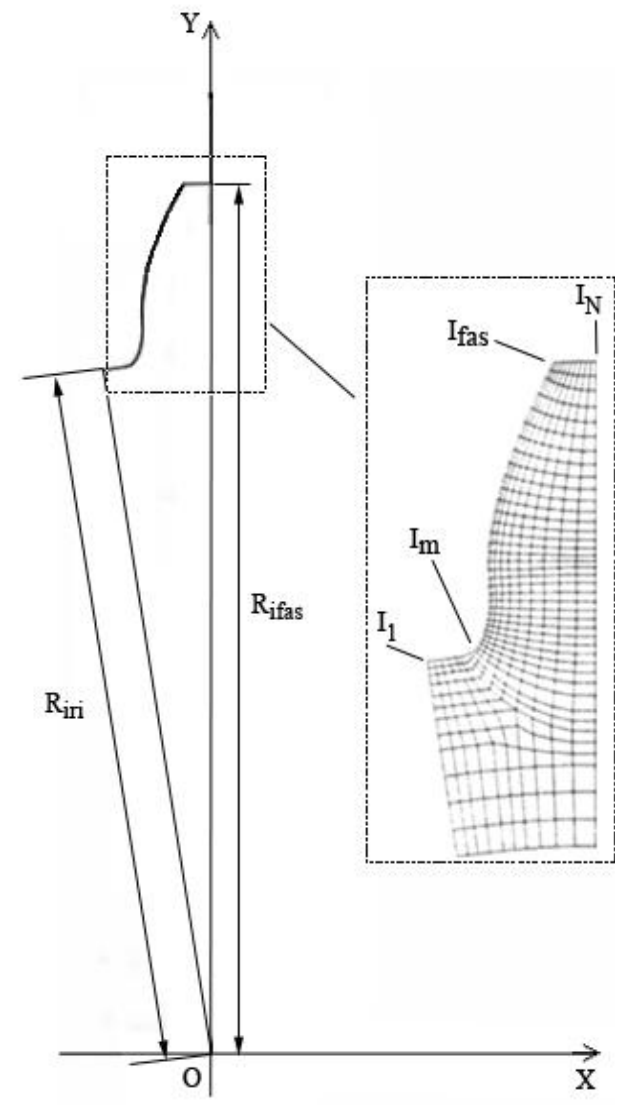

Figure 3. Tooth profile with relative indexes.

\subsection{Initial subdivision}

Once the characteristic parameters of the tooth ${ }^{\mathrm{a}}$ are known, the tooth profile is delimited by the outside and root circles. Where $\mathrm{N}$, taken by the designer, is the number of subdivisions along the outer profile of the tooth, we make an initial subdivision with the following reservation:

$20 \cdot \mathrm{N} / 150$ subdivisions for the internal circular arc

$50 \cdot \mathrm{N} / 150$ subdivisions for the fillet profile

$75 \cdot \mathrm{N} / 150$ subdivisions for the active flank

$5 \cdot \mathrm{N} / 150$ subdivisions for the outside circular arc

The side of the tooth (fillet profile + active flank) is therefore characterised by the following number of subdivisions: $\quad \mathrm{I}_{\text {tot }}=(50+75) \cdot \mathrm{N} / 150$

The results of this first subdivision will form the basis for the subsequent refinement based on the area, if any,

\footnotetext{
${ }^{\mathrm{a}}$ For modular proportion gear teeth: number of teeth, module, pressure angle on the two sides.
}

where we will want the highest concentration of elements in order to thicken the mesh in a specific area.

Each subdivision of the profile is identified by an index $\mathrm{I}_{\mathrm{i}}$, with $1 \leq \mathrm{i} \leq \mathrm{N}$ increasing as the distance from the center of the wheel increases.

After having indicated with $I_{m}$ the index corresponding to the area in which we want the highest concentration of subdivisions, that is, the area where the mesh must be thickest and with $\omega$ the relationship, also defined by the designer, between maximum and minimum concentration, we identify the section in which the intervals are more sparse. If we obtain:

$I_{m}>I_{\text {tot }} / 2$ the distance of this section from the center of the wheel is lower than the distance of the interval at maximum concentration.

If, on the other hand, we obtain:

$\mathrm{I}_{\mathrm{m}}<\mathrm{I}_{\text {tot }} / 2$ then the distance of this section from the center of the wheel is greater than that of the interval at maximum concentration.

\subsubsection{First case: Im > Itot / 2}

In case of a section with a minimum concentration of subdivisions external to the section at maximum concentration, the following system of equations is developed:

$\left\{\begin{array}{l}\mathrm{R}_{(\mathrm{Ifas})}-\mathrm{R}_{(\mathrm{Ifas}-1)}=\mathrm{R}_{(\mathrm{Im}+1)}-\mathrm{R}_{(\mathrm{Im})}+\mathrm{K}_{\mathrm{y}} \cdot\left(\mathrm{I}_{\mathrm{fas}}-\mathrm{I}_{\mathrm{m}}-1\right) \\ \left(\mathrm{R}_{(\mathrm{Im}+1)}-\mathrm{R}_{(\mathrm{Im})}\right) \cdot \omega=\mathrm{R}_{(\mathrm{Ifas})}-\mathrm{R}_{(\mathrm{Ifas}-1)}\end{array}\right.$

$\mathrm{R}_{(\mathrm{i})}$ is the value of the radius at the $\mathrm{i}$-th subdivision, "I $\mathrm{fas}_{\text {" }}$ " the index "I" corresponding to the outside radius, " $\mathrm{K}_{\mathrm{y}}$ " is the constant radius increase between any two adjacent intervals ${ }^{b}$. The system (1) expresses the consistency of growth between adjacent intervals and the existence of a predetermined ratio, equal to $\omega$ between the interval of larger size and the interval of smaller size. From the previous system we obtain, for the increase $\mathrm{K}_{\mathrm{y}}$, the following expression:

$$
K_{y}=\frac{(\omega-1) \cdot\left(R_{(I m+1)}-R_{(I m)}\right)}{\left(I_{f a s}-I_{m}-1\right)}
$$

The condition of constant increase between two consecutive intervals makes it possible to define the interval to be subdivided as:

$\mathrm{R}_{\text {(Ifas) }}-\mathrm{R}_{(\text {Iri) }}=\left(\mathrm{I}_{\text {fas }}-\mathrm{I}_{\text {ri }}\right) \cdot\left(\mathrm{R}_{(\mathrm{Im}+1)}-\mathrm{R}_{(\mathrm{Im})}\right)+\mathrm{K}_{\mathrm{y}}\left(\mathrm{S}_{1}+\mathrm{S}_{2}\right)$

The index $\mathrm{I}_{\mathrm{ri}}$ identifies the first value of the index I on the fillet profile; $R_{(\text {Iri) }}$ therefore coincides with the value of the root radius and $\mathrm{R}_{(}$(fas), on the other hand, coincides with the value of the outside radius. The parameters $S_{1}$ and $\mathrm{S}_{2}$, on the other hand, are defined as follows:

$$
\begin{aligned}
& \mathrm{S}_{1}=1+2+3+4+5+\ldots . .+\left(\mathrm{I}_{\mathrm{fas}}-\mathrm{I}_{\mathrm{m}}-1\right) \\
& \mathrm{S}_{2}=1+2+3+4+5+\ldots . .+\left(\mathrm{I}_{\mathrm{m}}-\mathrm{I}_{\mathrm{ri}}-1\right)
\end{aligned}
$$

\footnotetext{
${ }^{b}$ With the exception of those which share the point of subdivision with the index $\mathrm{I}_{\mathrm{m}}$ : intervals ranging, that is, between $R_{(I m+1)}$ and $R_{(I m)}$ and the interval between $R_{(I m)}$ and $\mathrm{R}_{(\mathrm{Im}-1)}$, equal intervals.
} 
As proposed, each interval differs from the previous one by a constant quantity $\mathrm{K}$; indicating with $\eta$ the minimum distance between two successive points of subdivision $\left(\eta=R_{(I m+1)}-R_{(I m)}=R_{(I m)}-R_{(I m-1)}\right)$, the thickness of each interval can be expressed as the sum of $\eta$ and of as many increments $K_{y}$ as the intervals separating it from the thickness $\eta$ interval.

In other words, for any value $X>I_{m}$, with $I_{r i}>X>I_{\text {fas, }}$, we have the following relationship:

$\mathrm{R}_{(\mathrm{X}+1)}-\mathrm{R}_{(\mathrm{X})}=\eta+\mathrm{K}_{\mathrm{y}}\left(\mathrm{X}-\mathrm{I}_{\mathrm{m}}-1\right)$

While for $\mathrm{X}<\mathrm{I}_{\mathrm{m}}$ the corresponding one applies:

$\mathrm{R}_{(\mathrm{X})}-\mathrm{R}_{(\mathrm{X}-1)}=\eta+\mathrm{K}_{\mathrm{y}}\left(\mathrm{X}-\mathrm{I}_{\mathrm{m}}-1\right)$

There follow the (4) referred to above.

Relation (3) expresses the fact that the total height of the tooth can be expressed as the sum of $\left(I_{\text {fas }}-I_{\text {ri }}\right)$ intervals and of many increments $\mathrm{K}_{\mathrm{y}}$ obtained precisely from the sum of $S_{1}$ and $S_{2}$ as shown above.

From (2) and (3) we obtain the following expression :

$\mathrm{R}_{\text {(Ifas) }}-\mathrm{R}_{\text {(Iri) }}=\left(\mathrm{I}_{\text {fas }}-\mathrm{I}_{\mathrm{ri}}\right) \eta+\eta\left(\mathrm{S}_{1}+\mathrm{S}_{2}\right) \cdot(\omega-1) /\left(\mathrm{I}_{\text {fas }}-\mathrm{I}_{\mathrm{m}}-1\right)$

From this it is possible to obtain the expression for $\eta$, that is, the size of the minimum interval:

$$
\eta=R_{(I m+1)}-R_{(I m)}=\frac{\left(R_{(I f a s)}-R_{(I r i)}\right)}{\frac{\left(I_{\text {fas }}-I_{\text {ri }}\right)+\left(S_{1}+S_{2}\right) \cdot(\omega-1)}{\left(I_{\text {fas }}-I_{m}-1\right)}}
$$

All the second member sizes are and can be defined quickly based on the characteristics of the tooth and on the data entered by the user; after having obtained $\eta$ it is very simple to calculate $\mathrm{K}_{\mathrm{y}}$ from (2):

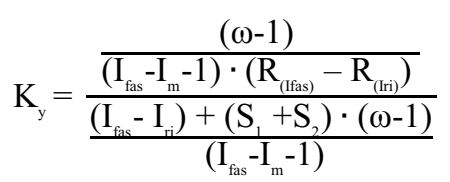

This expression, duly simplified, takes on the following form:

$$
\mathrm{K}_{\mathrm{y}}=\frac{(\omega-1) \cdot\left(\mathrm{R}_{\text {(fras) }}-\mathrm{R}_{\text {(fri) }}\right)}{\left(\mathrm{I}_{\text {fas }}-\mathrm{I}_{\mathrm{ri}}\right) \cdot\left(\mathrm{I}_{\text {fas }}-\mathrm{I}_{\mathrm{m}}-1\right)+\left(\mathrm{S}_{1}+\mathrm{S}_{2}\right) \cdot(\omega-1)}
$$

Expression (10) defines the increase between two successive intervals.

\subsubsection{2nd case: Im > Itot / 2}

Similarly, the same sizes are defined, $\eta$ and $K_{y}$, in the case of a section with a minimum concentration of subdivisions internal to the section at maximum concentration; in this case, obviously, the starting equations differ:

$$
\left\{\begin{array}{c}
\mathrm{R}_{(\mathrm{Iri}+1)}-\mathrm{R}_{(\mathrm{Iri})}=\mathrm{R}_{(\mathrm{Im})}-\mathrm{R}_{(\mathrm{Im}-1)}+\mathrm{K}_{\mathrm{y}}\left(\mathrm{I}_{\mathrm{m}}-\mathrm{I}_{\mathrm{ri}}-1\right) \\
\left(\mathrm{R}_{(\mathrm{Im})}-\mathrm{R}_{(\mathrm{Im}-1)}\right) \cdot \omega=\mathrm{R}_{(\mathrm{Iri}+1)}-\mathrm{R}_{(\mathrm{Iri})}
\end{array}\right.
$$

From which

$$
K y=\frac{(\omega-1) \cdot\left(R_{(I m+1)}-R_{(I m)}\right)}{\left(I_{m}-I_{r i}-1\right)}
$$

The latter replaced in (3), which remains unvaried, provides the expression of $\eta$ in the second case:

$$
\eta=R_{(\mathrm{Im})}-\mathrm{R}_{\text {(Im-1) }}=\frac{\mathrm{R}_{(\mathrm{Ifas})}-\mathrm{R}_{\text {(Iri) }}}{\frac{\left(\mathrm{I}_{\mathrm{fas}}-\mathrm{I}_{\mathrm{ri}}\right)+\left(\mathrm{S}_{1}+\mathrm{S}_{2}\right) \cdot(\omega-1)}{\left(\mathrm{I}_{\mathrm{m}}-\mathrm{I}_{\mathrm{ri}}-1\right)}}
$$

and, hence, of $\mathrm{K}_{\mathrm{y}}$ :

$$
\mathrm{K}_{\mathrm{y}}=\frac{(\omega-1) \cdot\left(\mathrm{R}_{(\text {Ifas })}-\mathrm{R}_{(\text {Iri })}\right)}{\left(\mathrm{I}_{\mathrm{fas}}-\mathrm{I}_{\mathrm{ri}}\right) \cdot\left(\mathrm{I}_{\mathrm{m}}-\mathrm{I}_{\mathrm{ri}}-1\right)+\left(\mathrm{S}_{1}+\mathrm{S}_{2}\right) \cdot(\omega-1)}
$$

\section{Definition by points of the tooth profile}

The subdivision of the interval identified by outside and root radiuses permits to identify $\mathrm{N}$ subdivision points on each of the two tooth profiles; except for symmetrical toothings, these points lie at different levels, that is, the distance of the i-th point of the first profile from the center of the wheel (radius) is generally different from that of the corresponding i-th point of the second profile. For a rational mesh of the tooth, in particular for the tracking of the "parallels", however, the corresponding points on the opposite profiles should lie at the same radius; to that end, an iterative process is developed in order to identify the point of equal radius of the opposite profile, thus making it possible to create, on toothings having the same module and number of teeth, although a different value of the second pressure angle, meshes comparable between them as they have been realized based on the same first profile. The point of equal radius on the second profile is identified by seeking the first point of radius greater than the corresponding point on the first profile. The radius of a quantity $\Delta \mathrm{r}$ is therefore reduced and this operation is repeated until the radius drops below the radius on the first profile; when this occurs $\Delta \mathrm{r}$ is halved and is added to the obtained value, repeating and changing the sign whenever the radius on the first profile is exceeded. The process continues until $\Delta \mathrm{r}$ drops below a threshold equal to the set degree of accuracy.

\section{Identification of the circular arcs perpendicular to the profile in the points with equal radius}

After having identified the points of equal radius on the opposite profiles, said points with perpendicular circular arcs are joined with both profiles at the aforesaid points of equal radius. In order to interpolate a circular arc between two points of equal radius, it is first necessary to determine the tangents to the two profiles at the aforesaid points (in the case of symmetrical teeth the two tangents have the same angular coefficient, although of the opposite sign). The tangent of the i-th point of the profile is defined as the straight line with angular coefficient given by the average of the angular 
coefficients of the two straight lines passing, respectively, through points $(i, i+1)$ and (i, i-1). Having thus defined the tangents on the two opposite profiles at the points of equal radius, we obtain the average value of the tangent to the two profiles and, from this, the center of the circular arc sought, which is therefore almost perpendicular to the two profiles.

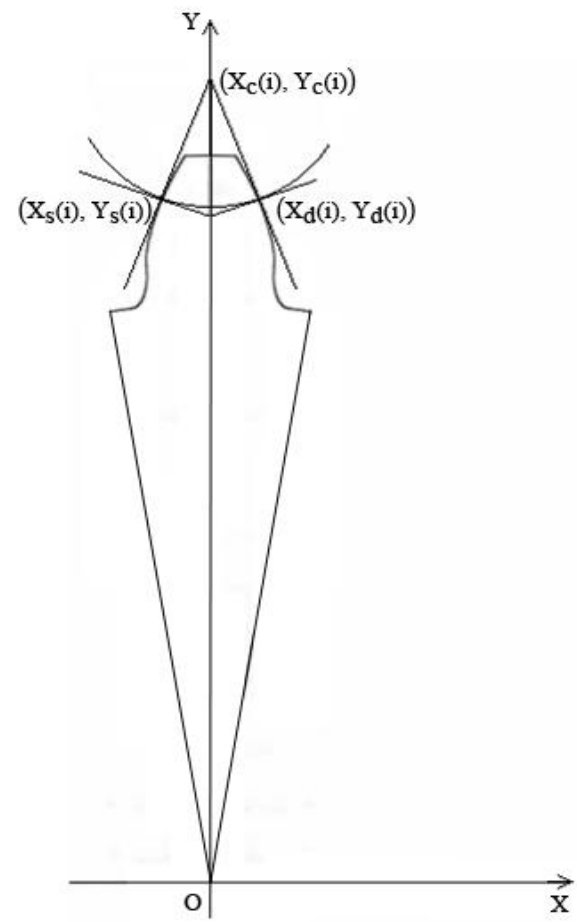

Figure 4. Coordinates of a circular arc center.

We assume an XY coordinate system originating from the center of the wheel and axis $\mathrm{Y}$ coinciding with the radial axis of the tooth.

The ordinate $\mathrm{X}_{\mathrm{c}}(\mathrm{i})$ of the $\mathrm{i}$-th center of the arc is given by the mean value of the ordinates $X_{s}(i)$, relating to the point belonging to the left profile and $X_{d}(i)$, relating to the point belonging to the right profile, while to identify the abscissa $Y_{c}(i)$, the belonging of the center to the tangent of the profile is set (see figure 4).

After having determined the coordinates of the center, we determine the radius of curvature of the arc, hence the equation of the circle of which the arc is part.

The analytical procedure is developed on the basis of the coordinates $X_{s}(i), Y_{s}(i)$ and $X_{d}(i), Y_{d}(i)$ of the points of equal radius.

First we calculate the angular coefficients of the tangents to the left and right profiles in proximity of the i-th point:

$$
\begin{array}{ll}
\mathrm{m}_{\mathrm{s} 1 \mathrm{i}}=\frac{\mathrm{Y}_{\mathrm{s}}(\mathrm{i}+1)-\mathrm{Y}_{\mathrm{s}}(\mathrm{i})}{\mathrm{X}_{\mathrm{s}}(\mathrm{i}+1)-\mathrm{X}_{\mathrm{s}}(\mathrm{i})}(15) & \mathrm{m}_{\mathrm{s} 2 \mathrm{i}}=\frac{\mathrm{Y}_{\mathrm{s}}(\mathrm{i})-\mathrm{Y}_{\mathrm{s}}(\mathrm{i}-1)}{\mathrm{X}_{\mathrm{s}}(\mathrm{i})-\mathrm{X}_{\mathrm{s}}(\mathrm{i}-1)} \\
\mathrm{m}_{\mathrm{d} 1 \mathrm{i}}=\frac{\mathrm{Y}_{\mathrm{d}}(\mathrm{i}+1)-\mathrm{Y}_{\mathrm{d}}(\mathrm{i})}{\mathrm{X}_{\mathrm{d}}(\mathrm{i}+1)-\mathrm{X}_{\mathrm{d}}(\mathrm{i})}(17) & \mathrm{m}_{\mathrm{d} 2 \mathrm{i}}=\frac{\mathrm{Y}_{\mathrm{d}}(\mathrm{i})-\mathrm{Y}_{\mathrm{d}}(\mathrm{i}-1)}{\mathrm{X}_{\mathrm{d}}(\mathrm{i})-\mathrm{X}_{\mathrm{d}}(\mathrm{i}-1)}
\end{array}
$$

The angular coefficients of the tangents to the right and left profiles are determined as the average of the previous ones: $\mathrm{m}_{\mathrm{si}}=\frac{\mathrm{m}_{\mathrm{s} 1}(\mathrm{i})+\mathrm{m}_{\mathrm{s} 2}(\mathrm{i})}{2}$$$
\mathrm{m}_{\mathrm{di}}=\frac{\mathrm{m}_{\mathrm{d} 1}(\mathrm{i})+\mathrm{m}_{\mathrm{d} 2}(\mathrm{i})}{2}
$$

The angular coefficient of the average tangent is given by:

$\mathrm{m}_{\mathrm{i}}=\frac{\left|\mathrm{m}_{\mathrm{s}}(\mathrm{i})\right|+\left|\mathrm{m}_{\mathrm{d}}(\mathrm{i})\right|}{2}$

which, on the two opposite profiles, will acquire the corresponding sign.

The equations of the tangents to the profiles are therefore the following:

$\mathrm{Y}_{\mathrm{i}}=\mathrm{m}_{\mathrm{i}} \mathrm{X}+\mathrm{q}_{\mathrm{s}}$$$
\mathrm{Y}_{\mathrm{i}}=-\mathrm{m}_{\mathrm{i}} \mathrm{X}+\mathrm{q}_{\mathrm{d}}
$$

where:

$\mathrm{q}_{\mathrm{s}}=\mathrm{Y}_{\mathrm{s}(\mathrm{i})}-\mathrm{m}_{\mathrm{i}} \mathrm{X}_{\mathrm{s}(\mathrm{i})}$

$\mathrm{q}_{\mathrm{d}}=\mathrm{Y}_{\mathrm{d}(\mathrm{i})}-\mathrm{m}_{\mathrm{i}} \mathrm{X}_{\mathrm{d}(\mathrm{i})}$

We then obtain the ordinate $\mathrm{Xc}(\mathrm{i})$ of the center as:

$X_{c}(i)=\frac{X_{s}(i)+X_{d}(i)}{2}$

and the ordinate $\mathrm{Y}_{\mathrm{c}}(\mathrm{i})$, imposing the belonging of the center to the tangent to the profile; once the tangent has been determined, by imposing the passage through the tangent point we get:

$\mathrm{Y}_{\mathrm{c}(\mathrm{i})}=\mathrm{m}_{\mathrm{i}} \mathrm{X}_{\mathrm{c}(\mathrm{i})}+\mathrm{q}_{\mathrm{s}}$

Having thus defined the coordinates of the center, we then define the radius as the distance of one of the tangent points from the center:

$R(i)=\sqrt{\left(X_{c}(i)-X_{s}(i)\right)^{2}+\left(Y_{c}(i)-Y_{s}(i)\right)^{2}}$

At this stage, the equation of the circumference can be easily obtained in the form

$\mathrm{X}^{2}+\mathrm{Y}^{2}+\mathrm{aX}+\mathrm{bY}+\mathrm{c}=0$

where:

$$
\begin{aligned}
& a=-2 X_{c}(i) \\
& b=-2 Y_{c}(i) \\
& c=\left[X_{c}(i)\right]^{2}+\left[Y_{c}(i)\right]^{2}-[R(i)]^{2}
\end{aligned}
$$

Given the need to identify the arc included between the points of equal distance from the center of the wheel, the equation of the circle must be accompanied by the following restrictions on the $\mathrm{Y}$ coordinate:

$$
\begin{array}{ll}
Y_{\mathrm{i}}<\mathrm{Y}_{\mathrm{s}}(\mathrm{i}) & \text { if } \mathrm{Y}_{\mathrm{c}}(\mathrm{i})>\mathrm{Y}_{\mathrm{s}}(\mathrm{i}) \\
\mathrm{Y}_{\mathrm{i}}>\mathrm{Y}_{\mathrm{s}}(\mathrm{i}) & \text { if } \mathrm{Y}_{\mathrm{c}}(\mathrm{i})<\mathrm{Y}_{\mathrm{s}}(\mathrm{i})
\end{array}
$$

By applying the procedure described above to all the points of subdivision of the profile, we get the system of "parallels" of the mesh (see figure 5). 


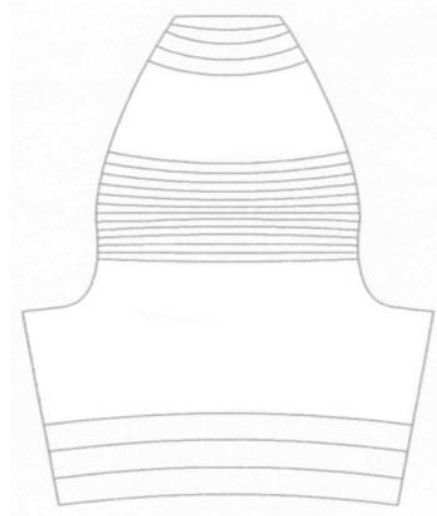

Figure 5. System of "parallels" of the mesh.

This procedure may present problems in the case of asymmetrical teeth: the fact that there may be areas of the profiles with a tangent of the same sign makes it impossible to interpolate circles that satisfy the set requirements; the solution to this problem will be addressed separately.

\section{Principle of subdivision of the arcs}

The subdivision of arcs makes it possible to create the mesh, generating a series of points on each "parallel", each of which will be crossed by one of the "meridians".

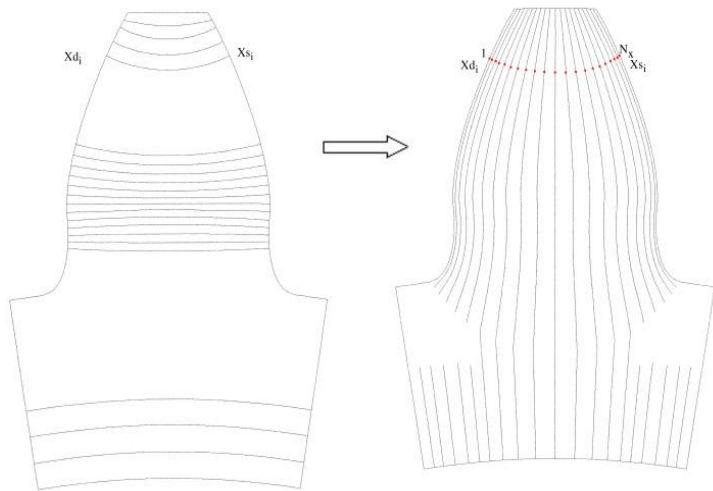

Figure 6. Subdivision of the arcs.

The basic principle of arc subdivision (see fig. 6) is based on the requirement of the most "squared" elements possible in the area with maximum concentration; this requirement will define the increase to be given to the minimum size of the interval on the arc, which size is known and equal to the value already defined for the vertical subdivision of the profile. The first check to be carried out concerns the number of set subdivisions: this will permit a number of intervals sized at least; once this has been achieved, we then look for the increase to be attributed to each interval so as to cover the entire arc with gradually increasing elements of the constant quantity $\mathrm{K}_{\mathrm{x}}$ to be determined. After having determined the coordinates of the midpoint of the arc, we then calculate the value of the increase $\mathrm{K}_{\mathrm{x}}$ as follows: where $\mathrm{N}_{\mathrm{x}}$ is the number of subdivisions for the single arc and $\mathrm{X}_{\mathrm{m}}$ the ordinate of the midpoint of the arc, having indicated as $X_{d}$ and $X_{s}$ the ordinates of the points on the right and on the left profiles, respectively, we get:
$\mathrm{X}_{\mathrm{d}}-\mathrm{X}_{\mathrm{s}}=\eta \mathrm{N}_{\mathrm{x}}+2 \mathrm{~K}_{\mathrm{x}} \mathrm{S}$

From which we obtain:

$\mathrm{K}_{\mathrm{x}}=\frac{\mathrm{X}_{\mathrm{d}}-\mathrm{X}_{\mathrm{s}}-\mathrm{N}_{\mathrm{x}} \eta}{2 \cdot \mathrm{s}}$

which provides the expression sought for $\mathrm{K}_{\mathrm{x}}$; in it $\mathrm{S}$ obviously takes on the meaning already seen in the case of the vertical subdivision of the tooth for $S_{1}$ and $S_{2}$ : after the user has set the value $\mathrm{J}_{\mathrm{m}}$ where the maximum concentration is desired, $\mathrm{S}$ is defined as: $\mathrm{S}=\mathrm{S}_{\mathrm{a}}+\mathrm{S}_{\mathrm{b}}$, where:

$S_{a}=1+2+3+\cdots+\left(j_{m}-1\right)$
$S_{b}=1+2+3+\cdots+\left(\frac{N_{x}}{2}-j_{m}-1\right)$

\section{Identification of the mesh in areas with profiles having a tangent of equal sign}

Especially in the case of asymmetrical teeth, the problem may arise of meshing areas of the tooth whose opposite profiles have a tangent of equal sign; in that case it is not possible to interpolate a circular arc: a different strategy is therefore identified. The identification of the arcs is suspended, the suppressed arcs are counted and equal number of subdivisions in a vertical direction is introduced anew, repeating the procedure for all the vertical intervals identified by the pairs of corresponding points on the arcs facing the area in question. Once the vertical subdivision of the interval has been carried out, an ordinate is attributed to each of these subdivisions, dividing the interval in the $\mathrm{X}$ direction in a number of parts equal to the number of suppressed arcs.

\section{Discretization of the profile in the vicinity of angular points}

The presence of points on the tooth profile in which there is a sudden change in the radius of curvature of the profile leads to abnormal situations, with the adjacent arcs having an opposite radius of curvature; this generates elements of abnormal size, or arcs intersecting one another.

\subsection{Solution in the event of intersecting arcs}

In this case the calculation program automatically deletes the intersecting arcs. The area of the tooth thus "emptied" will therefore need to undergo a new mesh process. For this purpose, it is first necessary to check whether the cleared area allows the insertion of parallels, depending on the size of the adjacent elements; if this is not possible, the nodes on the surviving arcs will simply be joined with straight segments thus recreating the meridians in the area in question. If, on the other hand, it is possible to insert parallels (or if the emptied area has multiple "radial" sizes compared with the adjacent elements), a number of parallels equal to the identified will be entered. 


\subsection{Solution in case of areas with thinning of the mesh due to the opposite curvature of the adjacent arcs}

This situation occurs frequently in the fillet area of the tooth, even in the case of symmetrical teeth; the solution to this problem is in this case extremely simple: it will suffice to check the size of the elements, inserting a parallel passing through the midpoints of the radial segments linking the nodes of the adjacent arcs whenever the size of the elements becomes such as to be at least double the previous element. In the case where the ratio between the size of the elements is even greater, similarly to what is set out in the previous paragraph, the programme will enter more parallels.

\section{Verification of the size of the elements.}

In order to obtain a high level of reliability of the FEM calculation, the discretized elements must have the most regular shape possible; in order to ensure this property, an additional check is carried out by verifying that on all the elements the relationship between the sides of the single element does not exceed the value $1 / 3$, in which case an additional subdivision parallel is introduced, thus avoiding the risk of having disproportioned elements.

\section{Conclusions}

The algorithms and strategies illustrated above permit to carry out a tooth mesh simply by starting from the parameters of the same tooth. The translation of these algorithms into a calculation software permits to automate the process and to quickly analyse under the FEM any asymmetric gear so as to compare its characteristics with the equivalent traditional tooth, making it possible to predict the performance variation corresponding to the variation of the second pressure angle and, hence, to size the asymmetrical tooth.

\section{References}

1. A. Kapelevich, "Direct gear design for asymmetric tooth gears" Mechanisms and Machine Science, 34, pp. 117-143, (2016)

2. S. Ekwaro-Osire, I. Durukan, F.M. Alemayehu, "Experimental and probabilistic analysis of asymmetric gear tooth. Conference Proceedings of the Society for Experimental Mechanics Series, 5, pp. 207-212, (2011)

3. A. Sanders, D. R. Houser, A. Kahraman, J. Harianto, S. Shon, "An experimental investigation of the effect of tooth asymmetry and tooth root shape on root stresses and single tooth bending fatigue life of gear teeth." Proceedings of the ASME Design Engineering Technical Conference, 8, pp. 297-305. (2011).

4. G. Di Francesco, S. Marini, "Asymmetric teeth: bending stress calculation", Gear Technology (MarApr 2007), Randall Publishing inc., Elk Grove Village, IL USA (2007)

5. R. Thirumurugan, C.C.C. Deepak, "Design and analysis of asymmetrical spur gear drive for automobile gear box application", Applied Mechanics and Materials, 592-594, pp. 2277-2281, (2014).

6. G. Di Francesco, S. Marini, "Tensioni di flessione di dentature asimmetriche e dimensionamento", Organi di Trasmissione (April 2005), Tecniche Nuove, Milan (2005)

7. G. Di Francesco, S. Marini, "Structural Analysis of Asymmetrical Teeth: Reduction of Size and Weight" Gear Technology, Randall Publishing inc. Sept- Oct. 1997, Elk Grove Village IL. U.S.A.(1997)

8. Di Francesco, S. Marini, “Asymmetrical gear wheel design: determining the bending stress in relation to the degree of asymmetry", TMT 2004, Trends in the development of machinery and associated technology, Neum (2004)

9. G. Di Francesco, S. Marini, "Dentature asimmetriche: evoluzione e procedura analitica per il dimensionamento" Organi di Trasmissione, Tecniche Nuove, Milano, (1998)

10. G. Di Francesco, S. Marini, G. Grasso, C. Clienti, "Asymmetric gear wheel thermographic analysis", Colloque Photomecanique, Étude du comportement des matèriaux et des structures, Albi (2004)

11. G. Di Francesco, S. Marini, "Asymmetrical gear wheels: automatized procedure for the design", International Conference on Gears, Munich 2005

12. G. Di Francesco, S. Marini, "Adattamento della procedura ISO C alle dentature asimmetriche", XXXIV Convegno AIAS, Milan (2005)

13. G. Di Francesco, S. Marini, "Ruote a denti asimmetrici: procedura automatizzata per il dimensionamento", Organi di Trasmissione (February 2008), Tecniche Nuove, Milan (2008) 